\title{
Familia-enpresen orientazio ekintzailea Mendebaldeko Saharan: testuinguruaren garrantzia
}

\author{
Unai Arzubiaga*, Amaia Maseda*, Brahim Baba Yusuf**, Estibaliz Rodríguez ${ }^{\star \star *}$ \\ Finantza Ekonomia I Saila* (UPV/EHU), Enpresa Zuzendaritza Berrikuntzaren \\ eta Internazionalizazioaren Ikuspegitik Masterreko ikaslea** (UPV/EHU), \\ Finantza Ekonomia II Saila*** (UPV/EHU)
}

\begin{abstract}
Familia-enpresen orientazio ekintzailean (EO) testuinguruko faktoreek duten eraginak arreta handiagoa eskatzen du ikertzaileen aldetik. Era horretan, azterlan honek ikertzen du nola eragiten duten nazio mailako faktoreek EOaren eta familiaenpresen emaitzen arteko erlazioan. Zehazki, ikerlan honek ikertzen du nola bultzatzen edo geldiarazten duten erlijioak, historiak, egitura ekonomikoak, kulturak eta egoera politikoak erlazio hori aparteko ingurune batean: Mendebaldeko Saharan, hain zuzen. Asmo horrekin, ikerketan lortutako emaitzak plazaratu ditugu, zeinek egonkortasun politikoak, garapen-bidean dagoen egitura ekonomikoa izateak eta erlijio zein nazionalismotik eratorritako zenbait faktorek EOan dauzkaten onurak azpimarratzen baitituzte. Azkenik, azterlanaren aurkikuntzak eztabaidatu eta ondorio nagusiak laburbildu ditugu.
\end{abstract}

GAKO-HITZAK: Orientazio ekintzailea · Emaitzak · Familia-enpresa · Mendebaldeko Sahara.

Entrepreneurial orientation and results of family firms in Western Sahara: the importance of the context

The effect of context factors in the entrepreneurial orientation (EO) of family businesses deserves greater attention. Thus, the present study explores how national factors influence the EO-performance relationship in family businesses. In this sense, this work aims to analyze how religion, history, economic structure, culture and political situation contribute to strengthen or hinder the EO-business performance relationship in a context as unique as the Western Sahara. To that end, we show our findings that highlight that EO benefits from the following facts: political stability, a developing economic structure, and some factors derived from religion and nationalism. Finally, these findings are discussed and the main conclusions of this research are summarized.

KEY WORDS: Entrepreneurial orientation · Performance · Family firm - Western Sahara. 


\section{Sarrera ${ }^{1}$}

Gero eta gehiago dira familia-enpresen garrantzia, ekonomian oro har eta herrien garapenean bereziki, azpimarratzen dutenak (Sharma, Chrisman eta Gersick, 2012). Horrela, gero eta aldakorragoa eta dinamikoagoa den ingurune batean, non bezeroen beharrak abiadura azkarrean eraldatzen ari diren eta merkatuen lehia globala bilakatu den (Paunov, 2012), orientazio ekintzailea (EO) ezinbestekoa da izaera lehiakor bat mantendu eta bizirik irauteko (Archibugi, Filipetti eta Frenz, 2013). Zentzu horretan, enpresa mota hauek ikertzen dituzten ikertzaileen artean, EOaren azterketa gori-gorian dauden gaien artean bete-betean sartu da (Casillas, Moreno eta Barbero, 2011; Cruz eta Nordqvist, 2012; Naldi, Nordqvist, Sjöberg eta Wiklund, 2007). EOa enpresa baten ekintzailetzarako jarrera gisa definiturik (Covin eta Wales, 2012) eta berrikuntzarako, proaktibitaterako eta arriskuak hartzeko joeraterminoetan neurturik (Covin eta Slevin, 1991; Miller, 1983), literaturak honako ideia onartzen du: EO maila handiagoko enpresek, beste enpresa kontserbadoreagoekin alderatuta, emaitza hobeak lortzen dituzte (Rauch, Wiklund, Lumpkin eta Frese, 2009).

Hala eta guztiz ere, zenbait azterlan enpirikok EOaren eta familia-enpresen emaitzen arteko erlazioa testuinguru guztietan parekagarria ez dela nabariarazi dute, erlazioek ezberdintasunak aurkezten baitituzte bai beren izaeran bai eta beren intentsitate-mailan ere (Kollman eta Stockamnn, 2014; Van Doorn, Jansen, Van den Bosch eta Volberda, 2013). Zehazki, Anderson eta Eshima-ren (2013) ikerlanak ingurunetik ingurunera erlazio hori aldatzen doala erakusten du, testuinguruaren arabera aldatzen diren aldagai moderatzaile ezberdinen zeharkako efektuak sakonago aztertzearen beharra azpimarratuz (Saeed, Yousafzai eta Engelen, 2014). Era horretan, aldagai horien azterketak testuinguruen arabera agertzen diren aldeak ulertzen lagunduko luke (Covin, Green eta Slevin, 2006; Baker eta Sinkula, 2009). Izan ere, ager litezkeen erlijioa, egonkortasun politiko instituzionala, egitura ekonomikoa, ohiturak zein historia bezalako tokian tokiko aldagaiek EO moduko joera estrategiko batean eragin handia izan baitezakete (Kirca, Jayachandran eta Bearden, 2005).

Dena den, faktore horiek EOaren eta familia-enpresen emaitzen arteko erlazioan daukaten eraginak ulermen sakonago baten beharra dauka (Suddaby, Bruton, eta $\mathrm{Si}, 2015)$, eragin horiek zein terminotan gauzatzen diren ezagutu eta horietara indarrak bideratu ahal izateko (Saeed et al., 2014). Horregatik, azterlan honek faktore horiek EOak emaitzetan duen eragina nola bultzatzen edo geldiarazten duten ulertzea du xede. Zehatzago esanda, egonkortasun politiko instituzionalak, egitura ekonomikoak, ohiturek, historiak eta erlijioak izan ditzaketen eraginak aztertu dira. Hori helburu hartuta, zinez berezia den testuingurua hartu dugu erreferentziatzat: Mendebaldeko Sahara, non aldagai moderatzaile horiek oso muturreko balioak hartzen dituzten, horri esker, ondorio zehatzagoak eta ulergarriagoak atera

1. Ikerlan hau, Enpresa Zuzendaritza Berrikuntzaren eta Internazionalizazioaren Ikuspegitik Masterrean (UPV/EHU) Brahim Baba Yusuf ikasleak garatu eta Unai Arzubiaga zein Amaia Maseda irakasleek zuzenduriko Efecto de los factores supra-empresariales en la orientación emprendedora y la innovación de las empresas familiares: evidencias del Sahara Occidental y Euskadi Master Bukaerako Lanean oinarritu da. 
daitezkeelarik. Horrez gain, Mendebaldeko Saharan familiak historikoki izandako giza harremanen erdigune-paperak eta familiek, familia-enpresen sorkuntzaren bidez, garapen-bidean dauden ekonomietan jarduera ekonomikoaren ardatz izateko joerak familia-enpresen jarduera zinez interesgarria bihurtzen dute lurralde horretan (Pistrui, Huang, Welsch eta Jing, 2006), nahiz eta horien kopuruari dagokionez datu ofizialik ez izan.

Ikerlan honek EOaren ulermenean era ezberdinetan lagundu nahi du. Lehenik, nazio mailako faktoreek familia-enpresen EOa emaitza arrakastatsu bilakatzerakoan zein paper hartzen duten erakusten da. Horretarako, erlijioa, historia, ekonomia eta kultura dimentsioen analisi sakona burutu da, EOaren eta familia-enpresen emaitzen arteko erlazioan haien moderatzaile-papera ulertu ahal izateko. Zentzu horretan, faktore horien eragina sakonago ulertzeko xedez, analisia herri mailan burutu da (Tsui, Nifadkar eta Ou, 2007). Bigarrenik, ikerlan hau EOaren eta familia-enpresen emaitzen arteko erlazioaren ulermenean aurrera egiteko orain arte aztertu ez den testuinguru berri batean kokatzen da: Mendebaldeko Saharan. Testuinguru horren berezitasunek, hots, islam erlijioaren nagusitasunak zein sistema tribalak berak enpresen antolaketan daukaten eraginek, mendebaldeko beste testuinguruetan bideratzen diren azterlanen ondorioak osatzea ahalbidetzen dute.

Ikerketa honen gainerako egitura honakoa da: sarreraren ondoren, hurrengo atalak lanaren garapenerako erabili den kontzeptu-esparrua aurkezten du, zeinak EOak familia-enpresen emaitzetan duen eragina azaltzeaz gain, Mendebaldeko Sahararen testuingurua argitzen duen. Hirugarren puntuak erabilitako metodologia zehazten du, laugarren atalean lortutako emaitzak deskribatu eta horien eztabaida garatu ahal izateko. Azken atalean, azterlanaren ondorio nagusiak jasotzen dira.

\section{Kontzeptu-esparrua}

\subsection{Orientazio ekintzailearen efektua familia-enpresen emaitzetan}

Jarrera ekintzailea enpresaren biziraupen eta garapenerako garrantzi handiko aldagaia da (Kellermanns eta Eddleston, 2006; Rauch et al., 2009; Sciascia, Mazzola eta Chirico, 2013), enpresei merkatuaren beharrei erantzuten eta lehiarako abantaila berriak sortzen lagun diezaiekeelako (Hult, Snow eta Kandemir, 2003; Kollman eta Stockmann, 2014). Ekintzailetzarako joera hau Miller-ek (1983) sortutako eta Covin eta Slevin-ek (1989) zein Lumpkin eta Dess-ek (1996) garatutako EO izeneko konstruktu dimentsioaniztun baten bitartez neurtu da. Konstruktu horrek erakunde ezberdinen ekintzailetzarako joera zein enpresa baten ekintzailetzarako joera denbora-tarte desberdinetan alderatzea ahalbidetzen du (Arzubiaga, Iturralde eta Maseda, 2012). Konkretuki, EOa hiru dimentsioko konstruktu multidimentsional gisa onartua izan da era zabal batean. Hiru dimentsio horiek berrikuntzarako joera, arriskuak hartzeko joera eta proaktibitaterako joera dira, elkarren artean positiboki kobariatu behar duten dimentsioak, alegia (Covin eta Wales, 2012). Enpresa baten joera ekintzailea hiru alde horien menpe dago: lehiarako abantaila lortzeko asmoz enpresan aldaketak sortzeko eta berrikuntzan laguntzeko joera (berrikuntzarako joera) (Wang, 2008); enpresako nagusiek enpresa arriskuan jar dezaketen 
egitasmo arriskutsuak beren gain hartzeko joera (arriskuak hartzeko joera) (Hughes eta Morgan, 2007), eta, azkenik, beste enpresekin oldarkor lehiatzeko jarrera (proaktibitaterako joera) (Tang, Tang, Marino, Zhang eta Li, 2008).

Familia-enpresen testuinguruan, hainbat azterlanek ondorio ezberdinak iradoki dituzte familia-enpresek EOa sustatu edo mugatzen ote duten gaiari buruz (Chirico eta Nordqvist, 2010; Jaskiewicz, Combs eta Rau, 2015). Familia-enpresetan EO maila ezberdinak zergatik diren argitzeko, zenbait ikertzaile aldagarritasun horrek zeri erantzuten ote dion ikertzen saiatu dira, barne-faktoreak zein kanpo-faktoreak zeintzuk diren identifikatuz. Kanpo-faktoreei dagokienez, gehienbat ingurune lehiakorrak (Lumpkin eta Dess, 2001) eta harreman-sareak (Stam eta Elfring, 2008) EOan nola eragiten duten aztertu da. Barne-faktoreei dagokienez, zuzendari orokorraren ezaugarriek (Cruz eta Nordqvist, 2012), familiako belaunaldi ezberdinen esku-hartzeak (Casillas et al., 2011; Sciascia et al., 2013), epe luzerako edo epe motzerako orientazioa izatearen ezberdintasunak (Lumpkin, Brigham eta Moss, 2010) eta antolaketa-kulturak (Breugst, Patzelt, eta Rathgeber, 2015; Zahra, Hayton eta Salvato, 2004) EOan dauzkaten efektuak neurtu dira.

Azken urteotan, analisi enpiriko askok EOak enpresaren emaitza askotan eragin positiboa daukala frogatu dute (adib. Anderson eta Eshima, 2013; Semrau, Ambos eta Kraus, 2015; Moreno eta Casillas, 2008). Zentzu horretan, ikerlan batzuek EOaren eta emaitzen arteko korrelazio baxua aurkitu arren (Dimitratos, Lioukas eta Carter, 2004; Lumpkin eta Dess, 2001; Zahra, 1991), ikerlan gehienek EO maila altuak dituzten enpresek emaitza esanguratsuki hobeak lortzen dituztela ondorioztatu dute (Covin eta Slevin, 1989; Hult et al., 2003, Wiklund eta Shepherd, 2003). Rauch et al.-ek (2009), beren EOaren eta emaitzen arteko erlazioari buruzko meta-analisian, EOak eta enpresaren emaitzak korrelazio positibo ertaina $(r=0,24)$ daukatela ondorioztatu dute. Hala ere, erlazio horri buruz literaturan topatutako ondorio eta emaitzen aniztasunak, dela izaeran dela intentsitatean, kontuan hartuta, hura enpresaren beraren testuinguruaren araberakoa dela ondoriozta genezake (Anderson eta Eshima, 2013). Saeed et al.-en (2014) ikerlanean, non EOaren eta enpresaren emaitzen arteko erlazioari buruzko 177 ikerketa baino gehiagoko metaanalisia garatzen den, nazio mailako faktore batzuk (herriaren kultura, historia, egitura ekonomikoa, egonkortasun politikoa edo erlijioa) erabakigarriak izan daitezkeela azpimarratzen da.

Hau guztia kontuan harturik, azterlan honen analisia jorratzeko, estatu propiorik izan ez arren, sustrai eta jatorri-sentimendu bereziak dauzkan ingurune nazional bat hautatu da: Mendebaldeko Sahara. Ingurune horren xehetasunek aipatutako nazio mailako faktoreek EOaren eta familia-enpresen emaitzen arteko erlazioan nola eragiten duten azaltzen lagun dezakete batik bat. Hurrengo atalean, EOaren eta familia-enpresen emaitzen arteko erlazioari eragiten dioten Mendebaldeko Saharako testuinguruko faktoreak sakonki aztertuko dira: historia, egoera politikoa, egitura eta garapen ekonomikoa, kultura, ohiturak eta erlijioa, nagusiki. 


\subsection{Mendebaldeko Saharako testuingurua}

\subsubsection{Kokapena eta demografia}

Mendebaldeko Sahara Afrikako iparraldeko lurraldea da, Sahara basamortuko mendebaldeko eremu batean kokaturik dagoena, Ozeano Atlantikoaren urertzean.

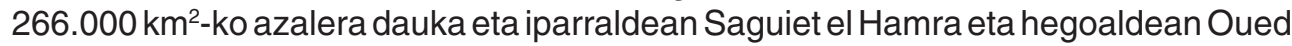
el Dahab (urrezko ibaia) barne hartzen ditu. Marokok mugatzen du Mendebaldeko Sahara iparraldetik, Aljeriak ekialdetik, Mauritaniak ekialde eta hegoaldetik, eta Ozeano Atlantikoak mendebaldetik. Gaur egungo saharar biztanleria 510.000 pertsonakoa da, bere hiriburuak, El Aaiún-ek, 300.000 biztanle dituelarik (Mundy, 2017).

\subsubsection{Egoera politikoa}

Mendebaldeko Sahararen egoera politikoa zein bere burujabetza nazioarte mailako eztabaida handiko gaiak dira. Mendebaldeko Sahara Nazio Batuen Erakundearen (NBE) 17 lurralde ez-autonomoen zerrendan dago, NBEren Deskolonizazio Batzordearen ikuskaritzapean (Corell, 2015). NBEren aburuz, Mendebaldeko Sahara delakoaren lurraldearen administraria Espainiako estatuak izaten jarraitzen duen arren, lurraldetik 1976an erretiratu zenez, Espainiako estatuak Sahararen kudeaketari eta horri buruzko nazio mailako edozein erantzukizuni uko egin zion. Horregatik, Mendebaldeko Sahararen burujabetza Marokok eta Saharako Errepublika Arabiar Demokratikoak (SEAD) aldarrikatzen dute. Hala ere, egungo Saharar herriaren zatiketa politiko eta administratiboa ulertzeko ezinbestekoa da 1975eko Marokoko Ibilaldi Berdearen garrantzia azpimarratzea. Gertaera horretan, saharar biztanleriaren gehiengo zabal batek bere bizilekuetatik ihes egin zuen, Marokok egoera hura baliatu zuelarik babeserako harresia eraikitzeko, saharar iheslarien itzulera eragozteko xedez (Es-Sweyih eta uld Ismail, 1998). Ondorioz, 1980tik aurrera, Mendebaldeko Sahararen lurraldea hiru zatitan banatuta geratu zen:

1) Lurralde okupatuak. Marokoren boterepean dagoen eskualdea da. Sahararen babeserako harresiaren barrualdea eta mendebaldea barneratzen dituzte eta lurraldearen \% 80 hartzen dute.

2) Lurralde askatuak, zeinen kontrola Fronte Polisarioak daukan. Hauek babeserako harresia eta Aljeria zein Mauritaniako mugen arteko eskualdea barne hartzen dute. Lurralde hauen eta errefuxiatuen kanpamenduen arteko harremanak etengabekoak dira.

3) Aljeriar lurraldeetan finkatutako errefuxiatuen kanpamenduak.

Arestian azaldutakoaren eraginez, Mendebaldeko Sahararen nortasun politikoa bukatugabeko prozesu batean dago murgildurik, etengabeko eboluzioan, bereziki gatazkaren izaerak zein bertako biztanleriaren ezaugarriek (sahararrak izan ala ez) hauspotuta. Zentzu horretan, lurraldearen banaketa politikoak eta eskualdeen antolamendu berriak ez dute sahararren eta ez sahararren arteko harremanik sustatzeko aukera askorik eman. Hala, lurraldearen identitateari buruz ezin daiteke baieztapen zehatzik egin. Oso goiz da lurraldearen identitate berria sortzeari buruz hitz egiteko, oraindik gizarte banatu batean gatazka politiko batek jarraitzen duelako eta adiskidetze-prozesu baten premia dagoelako (Martín eta Picón, 2015). 


\subsubsection{Egitura eta garapen ekonomikoa}

Azken hamarkadetan, Mendebaldeko Saharako egitura ekonomikoak etengabeko bilakaera izan du gaur egungo egoera ekonomikora heldu arte. Zenbait adituk Mendebaldeko Sahararen ekonomia hasiberritzat jotzen badute ere, saharar gizartea historikoki nahiko aberatsa izan da, itsasbazterreko arrantzatik, itsas landareetatik, palmondoen fruituetatik eta, hein handi batean, abeltzaintzatik biziraun duelarik (Smith, 2013). Halaber, aberastasun mineralak ere badituen arren bere lurraldean, hots, petrolioa eta zenbait metal, horiek Marokok okupatutako lurraldean dauden enpresa kanpotarrek kudeatzen dituzte (Smith, 2015). Horren eraginez, bizitzakalitatea bai eta diru-sarrera mailak ere Marokokoak baino nabarmenki baxuagoak dira. Bestalde, aipamen berezia merezi du Mendebaleko Sahararen lurretan ageri den fosfatoak, kalitate handikoa eta ustiapen merke eta errazekoa denak. Hala, fosfatoak Saharako ekonomiaren garapenerako oinarri sendoa izan beharko bazuen ere, 1975ean, Espainiako gobernuak lurraldearen kudeaketa Marokori eta Mauritaniari eman zienean Madrileko Akordioak zirela medio, administratzaile berriek bereganatu zituzten mineral horren zein arrantzaren irabaziak.

Gaur egungo Mendebaldeko Saharak bizi duen egoerarekin kritiko diren hainbat eragileren aburuz, aberastasun mineralak justifikatzen du Marokoren interesa Mendebaldeko Sahararen burujabetzan. Zehazki, petrolioak, Mendebaldeko Sahararen lurretan eta ur sakonetan dagoenak, bai eta arrantzarako ur aberatsak eta fosfatoak ere (Watch, 2015). Hala, Marokoko ondasun horiek logikak dioenarekin alderatuz, bestela ustiatzen ari dira. Arrantza-ondasunak, adibidez, bai bertako enpresek bai atzerriko enpresek ustiatzen dituzte. Mendebaldeko Saharako enpresei dagokienez, erkidegoko arrantzontziak nabarmentzen dira, Europar Batasunaren eta Marokoren arteko akordioaren babesarekin arrantzatzera bueltatu direnak. Oro har, itsasontzi txikiak dira, arrantzale marokoarrak kontratatu eta arrantza Afrikako lurraldeetan lehorreratu behar dutenak, El Aaiún eta Dajla-ko lonjak Mendebaldeko Saharako esanguratsuenak izanik (Smith, 2013).

Fosfatoaren ustiapena, aitzitik, bere osotasunean enpresa marokoar batek hartzen du bere gain, oraindik ere Mendebaldeko Sahara espainiar kolonia bat zen garaiko azpiegitura eta teknologia baliatuz, hots, mehaketarako makinak eta zinta garraiatzaileak (Watch, 2015). Petrolioaren ustiapenari dagokionez, esan beharra dago nahiz eta gaur egun hidrokarburoen erauzketa egon ez arren, 30 enpresa pribatuk daukatela hura ustiatzeko emakida. Horren gaineko interesaren zergatia, ordea, petrolio-poltsa bat espainiar, marokoar eta mendebaldeko saharar uretan banatuta egon daitekeela da (Smith, 2015).

Nekazaritzari dagokionez, azken urteotan Marokok Dakhla eskualdean, Mendebaldeko Saharako hego-ekialde okupatuan, ustiapen-estrategia berri bat gauzatu $\mathrm{du}$, marokoar jatorriko kolono ugari sartuz fruta eta barazki landa-eremuetan lan egiteko. Lurralde okupatuetatik etorritako produktuak, tomateak, pepinoak eta meloiak, esaterako, esportatu egiten dira Europa, Ipar Amerika eta garai batean Sobietar Batasuna osatzen zuten herrialdeetara. Horretarako, bi enpresa frantziarrek, Azura eta Idyl-ek, daukate produktu horien ekoizpen eta merkataritzaren ardura. $\mathrm{Bi}$ 
enpresa horiek 10.000 bat langileri eskaintzen diete lana, gehiengo zabala marokoar beharginak direlarik.

\subsubsection{Kultura eta usadioak}

Ikerlan historiko gehienak bat datoz saharar komunitatea etnikoki bereber, arabiar eta afrikarren nahasketa bat delako ideian. Nahaste hori egonik, sahararrak hasania izeneko dialekto arabiarrez hitz egiten duten bakarrak dira, islam sunita delarik VII. mendetik praktikatzen duten erlijio bakarra. Gizarte motari dagokionez, saharar gizartea oso hierarkizaturik dago, herriaren antolamenduan tribuak botere handia daukalarik (Martín eta Picón, 2015). Kolonizazio espainiarrak, iraultzak eta SEADen sorkuntzak saharar gizartearen eraldaketa modernoan parte hartu dute gaurko erronkei erantzuteko bide emanez.

SEADek gizarte-eredu berri bat sortu du, non saharar guztiak hiritar sentitzen diren eta iraganeko desadostasun eta norgehiagokak gainditzeko prest dauden. SEADek bere askatasunerako borrokan murgilduta dagoen herri-proiektu komuna lortzea du xede. XX. mendean Espainia, Maroko eta Mauritaniaren aurkako gudak sahararren baitan sentimendu nazionalista sendoa eta nazio mailako identitate irmoa errotu dituela nabarmena da. Herri sahararrak kultura independente eta ezberdin bat dauka ezaugarri bereizgarri bezala, zeinak bere arabiar eta afrikar izaera eta aintza islatzen dituen (Liceras, 2014). Saharar herriak, oro har, bere nortasuna, nazionalismoa eta balioak zaintzen dituen kultura propio bat babestea lortu du (Zunes eta Mundy, 2010). Mendebaldeko Saharan, ezaguerak, artea, sinesmenak, legea, tradizioak eta ohitura guztiak belaunaldiz belaunaldi ikasten dira, bai errefuxiatuen kanpamenduetan, bai lurralde okupatuetan ere (Kingsbury, 2016).

El Aaiún-en sorreraren eta Bucraa-ko fosfatoaren aurkikuntzaren ondoren, 1928an, hirietara fluxu migratzaile handia zein sahararren bizimoldean aldaketa erradikala gertatu ziren. Astiro-astiro, saharar familiak bizimolde berri eta moderno batera ohitzen hasi ziren 1975eko inbasio marokoarra heldu arte. Gertaera horrek saharar familien \% 80ren ihesa bultzatu zuen, berriz ere errefuxiatuen kanpamenduetan bizitzera eramanez (García-Guindo, 2016).

\subsubsection{Erlijioa}

Sahararrak musulman sunitak dira. Islama Mendebaldeko Saharara XI. mendean heldu zen, sufismo mistikoaren eta marabutismoaren arteko nahasketa eran. Historian zehar, islam ortodoxoa eta sufismoa elkarrekin bizi baziren ere, gaur egun, islam sunismo erlijioa zabalki ezarrita dago saharar biztanlerian: sahararren gehiengo batek bere burua praktikantetzat edo erlijioan aktibotzat dauka.

\section{Metodologia eta lagina}

\subsection{Metodologia}

Arestian aipatutako ikerketa-galderei erantzuteko asmoz, azterlan hau «Grounded theory» edo datuen teoria delakoan oinarritzen da (Glaser eta Strauss, 1967), 
horretarako kasu-azterketa deritzon teknika erabiliz (Eisenhardt eta Graebner, 2007). Teoria horren erabilera zabalki erabili eta aintzatetsia izan da soziologia eta antropologia zientzietan, esaterako. Kudeaketa-arloan, ordea, duela urte gutxi lortu du dagoeneko onartutako teoriak hedatzeko edo teoria berriak eraikitzeko onespena (Khavul, Bruton eta Wood, 2009). Zentzu horretan, Eisenhardt-en (1989: 534) definizioaren arabera, kasu-azterketa «ingurune zehatz batean ematen den dinamikaren ulermenerako ikerketa-estrategia» da, teknika aproposa izanik gaur egungo gertakari sistemikoak eta testuinguru-faktoreetatik banatzen zailak direnak aztertzeko (Yin, 2003). Ikerlan honen kasuan, Mendebaldeko Saharako familiaenpresen ekintzailetzaren nondik norakoen azterketa esparru berria da. Horrela, zuzeneko behaketan eta unean uneko datuetan oinarritutako analisi kualitatiboak egokia dirudi existitzen ez den teoria bat garatu ahal izateko.

Laginaren aukeraketa komenientziazko laginketa teknika erabiliz egin da. Laginketa teorikoarekin alderatuz, kasu kopuruaren eta horien ezaugarriak aurretiaz zehaztu dira (Goulding, 2009), garatu nahi diren kontzeptu teorikoak gauzatzeko behar den lagin egokia aukeratzeko asmoz. Lagina aukeratzeko era honek ikertzaileak berak eragindako akatsaren arriskua dakar (Eisenhardt eta Graebner, 2007). Hori saihesteko, bai eta emaitzen orokortze analitikoa egiteko helburuarekin ere, bigarren mailako iturrien datuekin eta ikerketan lortutako erantzunekin triangulazio bat egin da (Cassia, De Massis eta Pizzurno, 2012; Woodside eta Baxter 2013).

Aukeratutako laginaren kasu ezberdinen analisian, enpresaren zuzendari orokorra aukeratu da solaskide elkarrizketetarako. Kargu hori zuzendaritza-erabaki inportanteenak hartzen dituena izateaz gain, enpresaren sail guztien zokoak oso ongi ezagutzen ditu eta erakundearen ikuspegi global bat ere izan ohi du (Jennings, Edwards, Jennings eta Delbridge, 2015; Kellermanns, Eddleston, Barnett eta Pearson, 2008). Hartara, ikerlan honetan lau familia-enpresaren zuzendari orokorra elkarrizketatu dugu.

Beraz, Mendebaldeko Saharan kokaturiko lau enpresa aztertu dira era zabalean, ikerketa honetan enpresen sektorearen efektuak izan dezakeen eragina kontrolatuta izateko asmoz. Lagin honek ahalbidetu du historiak, kulturak eta usadioek, garapen eta egitura ekonomikoak zein erlijioak EOaren eta familia-enpresen emaitzen arteko erlazioan daukaten efektua aztertzea. Landa-lana 2017ko ekainean eta uztailean burutu zen, aukeratutako kasuak «Grounded theory» delakoaren arabera aztertuz (Yin, 2003). Hurrengo atalean, lagina osatzen duten kasuak, banan-banan, azalduko ditugu. Aipatu beharrekoa da, enpresek konfidentzialtasuna eskatu zigutenez, izenordeak erabili direla haien deskribapenetan.

\subsection{Lagina}

\subsubsection{Eraikuntza-sektorea}

Atal honetan lan publikoak zein eraikuntza-sektoreko proiektu pribatuak egiten dituen Sahara Eraikuntzak (SE) enpresa aztertzen da. Hau da, SE enpresa edozein 
izaeratako eraikuntza-lanetan aritzen da, gaur egun hori delarik enpresaren negozio-linea garrantzitsuena. El Aaiún-en kokatua, hots, Mendebaldeko Saharako hiriburuan, eraikuntza-sektorean enpresa liderra da. 1999an sortu zen eta gaur egun 120 behargin ditu, sektorean eskarmentu handiko langile taldea izanik.

SEk administrazio publikoak eta erakunde pribatuak (enpresak eta banakakoak gehienbat) izan ohi ditu bezero, 2016an, 20.000.000 euroko fakturazioa lortu zuelarik. Bere zuzendaritza-taldeari dagokionez, 2 pertsona familiako kideak dira (zuzendari orokorra eta finantza-zuzendaria). Administrazio Kontseilua osatzen duten 7 pertsonetatik, ordea, 4 dira familiako senideak.

\subsubsection{Bulegoko altzarien diseinua eta salmenta-sektorea}

Sahara Altzariak (SA) 1992an El Aaiún-en sortutako enpresa da. Egongela, aulki eta mahaien diseinu eta ekoizpenean espezializatutako bulegoko altzarien diseinua eta salmenta-sektoreko negozioa da. SAk bere lurraldean ohitura handiko produktua diseinatu eta merkaturatzen du, unean uneko berrikuntzak kultura eta usadio propioei egokituz.

Enpresa honek Mendebaldeko Saharan dituen 20 dendetan (74 langile) diseinu berezidun altzari pertsonalizatuak eskaintzen ditu. 2016an 5.000.000 euroko fakturazioa izan zuen. Familiako hainbat kide eguneroko kudeaketan (orotara zuzendari sortzailearen $5 \mathrm{seme}$ ) eta Administrazio Kontseiluan aritzen dira (7 lagunetik 4 familiakoak dira).

\subsubsection{Informatika-sektorea}

Sahara Informatika (SI) informatika-sektorekoa da eta informatika-ekipoen salmentan (ordenagailu eramangarriak, inprimagailuak, monitoreak eta disko gogorrak), horien mantentze-lanetan eta beste hainbat zerbitzu profesional eskaintzen dihardu.

SI enpresa 2005ean sortu zen Mendebaldeko Saharako hiriburuan, El Aaiúnen. Eskarmentu handiko 53 tekniko informatikori ematen die lan eta zuzendari bat bakarrik dauka. Familia-enpresa da, non zuzendari bakar hori enpresaren sortzailearen semea den. Ez daukate Administrazio Kontseilurik. 2016an SIk 3.000.000 euroko fakturazioa izan zuen.

\subsubsection{Osasun-sektorea}

Azkenik, Sahara Osasuna (SO) enpresak parafarmazia eta bestelako osasun-, edertasun- eta ongizate-produktuak merkaturatzen ditu. Horrez gain, kosmetika eta norberaren higiene eta garbiketarako produktuak ere saltzen dituen enpresa berria da, El Aaiún-en 2015ean sortu zena. Tamainari dagokionez, 6 langile ditu eta familiak enpresa zuzentzeko ardura. Administrazio Kontseiluan hiru kide aritzen dira, denak ere familiaz kanpokoak. 2016an 1.000 .000 euroko fakturazioa izan zuen. 


\section{Emaitzen eztabaida}

\subsection{Testuinguru politikoa}

Egonkortasun politikoa da EOaren eta familia-enpresen emaitzen arteko erlazioan eragin handiena izan dezakeen faktorea. Egonkortasun politikoa, Gobernuak eta Administrazioak, ohiko gertakariak tarteko, egonkortasuna galtzearen probabilitate bezala uler daiteke. Kasu honetan, EOaren eta familia-enpresen emaitzen arteko erlazioa iraunkorragoa izango da testuinguru politikoa egonkorragoa denean. Oro har, EO maila altuagoko enpresek zein merkatuan berrikuntzak sartzen dituzten enpresek hobeto funtzionatzen baitute egoera egonkorretan. Izan ere, egoera egonkorrek ideien eskubideak zein haiek erabiltzeko eskubideak galtzearen arriskuak gutxitzen baitituzte (Wright, Pruthi eta Lockett, 2005).

Bestalde, egoera politikoa egonkorra ez denean, enpresek egindako inbertsioen desjabetzearen arriskua ager daiteke, hornitzaileen (finantza-erakundeak, aholkulariak, espezialistak... ekimen ekintzaileak aurrera eramateko beharrezkoak diren zerbitzuak) ezarpena ere eragotziz (Wiklund eta Shepherd, 2003). Hori izan daiteke Mendebaldeko Sahararen kasua, ingurune erabat nahasia, non produktu berriak sortzeko inbertsioak zaintzeko berme juridikoak falta diren. SE enpresakoen aburuz, enpresa atzerritarrek edota marokoarrek saharar lurraldeetan ezartzeko laguntzakizateak (baliabide naturalak - fosfatoa edoarrantza-hartzekolehentasuna eta zerga-gabezia, adibidez) bertako enpresek inbertsioak eta ekimen ekintzaileak egiterakoan desabantailak izatea eragiten du. Gainera, ez badiete atzerriko enpresei zergarik kobratzen, ez da dirurik egongo horrelako ekimen ekintzaileak babesten dituzten erakunde publikoak sortzeko. SI enpresak ezegonkortasunaren efektu txarra lurraldearen ekonomian oro har eta bere sektorean bereziki dituen eragin kaxkarrak azpimarratzen ditu. Enpresa horretakoek Mendebaldeko Saharako enpresentzat material berrian eta ekipo informatikoetan inbertsioak egiteak esfortzu ekonomiko handia dakarrela nabarmentzen dute. Horren arabera, bertako enpresek inbertsio horiei errendimendua atera ahal izateko egonkortasun-garai bat etorriko dela igarri behar dute. Oro har, Mendebaldeko Saharan, Europako herrialdeekin konparatuz, ondasunen bizitza erabilgarria nahiko luzatzen badute ere, ingurune politikoak gorabehera gutxi izatea behar dute produktu berriak sortzeko beharrezkoak diren inbertsioak egiteko.

Muturreko testuinguruko enpresa hauen baieztapenen aurrean, ondoriozta daiteke egonkortasun politikoak eragin handia daukala EOaren eta familia-enpresen emaitzen arteko erlazioan. Hain zuzen, testuinguru ezegonkorrak erlazio horren pizgarritzat hartzen baziren ere (Casillas et al., 2011), azterlan honen arabera, egonkortasuna ezinbesteko faktorea da.

\subsection{Garapen eta testuinguru ekonomikoa}

Ekonomien arteko ezberdintasun handienetako bat haien garapen-maila da. Zentzu horretan, alde nagusia honakoa da: ekonomia garatuek eskari finkoak izateaz gain, enpresen arteko lehia gogorra ere izaten dute; garapen-bidean dauden ekonomiek, ordea, eskarietan ziurgabetasuna pairatzen duten arren, hasieran 
merkatuan posizionamendu on bat lortzeko aukera gehiago eskaintzen dute (Arora eta Gambardella, 2015). SA enpresakoek ongi asko azaltzen dute zaila dela berrikuntza bat egiten den kasu askotan bezeroek hura nola baloratuko duten aurreikustea eta, are garrantzitsuagoa dena, hori ordaintzeko prest egongo ote diren. Askotan, egindako inbertsioak tarteko, produktu berriak edo hobetuak apur bat garestiagoak direla ahazten da, eta hori, ingurune txiro honetan, kontuan izan behar da. SEkoek, aitzitik, ekintzaileak haren ideia berritzailea aurrera eramateko gaitasuna izatekotan, lehiakideek hori egin bitartean denbora pasatzen dela onartzen dute.

Saeed et al.-ek (2014) iradokitzen dute gehien garatutako ekonomien eskariaren asebetetzeak kontsumitzaileek beren bizimoldea eta kontsumo-ohiturak mantentzea dakarrela, ekintzaileen produktu eta zerbitzu berrien sorrera gogogabetuz. Zentzu horretan, Marchi, Maria eta Micheli-k (2013) garapen-bidean dauden ekonomietan, produktu edo zerbitzu berri bat eskaintzen lehena izateak irabaziak lortzeko epe luzeagoak eskaintzen dituela erakusten dute. Merkatura heltzen lehena izatearen onurak aprobetxatzeko denbora hori urriagoa da ekonomia garatuetan, lehian parte hartzen duten lehiakideen ahalmena normalean handiagoa baita (Burgess eta Steenkamp 2006). Ondorioz, garapen-bidean dauden ekonomiak, ingurune honetako bezeroen erosteko ahalmenarekin bat datorren bitartean, EOtik eratorritako berrikuntzako irabaziak denbora luzeagoan lortzeko aproposagoak dira.

\subsection{Kultura eta usadio historikoen efektuak}

Herrien nortasuna haien gizartearen kulturan eta tradizio historikoetan islatzen da. Hala, abertzaletasun-sentimendu oso nabarmenak balio eta talde-portaerak errazago sustatzea ahalbidetzen du (Pistrui, Huang, Welsch eta Jing, 2006). Beraz, nazionalismoaren ondorioz sortutako kultura kolektiboak efektu bikoitza dauka ekimen ekintzaileak martxan jartzerakoan zein horien arrakasta errazterakoan.

Alde batetik, Balabanis, Diamantopoulos, Mueller eta Melewar-ek (2001) nazionalismoa joera kontserbadoretzat hartzen dute, zeinak berrikuntza eta ekimen ekintzaileak aurrera eramatea eragozten duen. Ildo horretatik, SO enpresak, sahararren existentzia eta izaera ezeztatzen duten herrietako enpresekin elkarlanean aritzeko erreparoak justifikatzen ditu. Horregatik, zenbait testuingurutan, Balabanis et al.-en (2001) baieztapena ulergarria da. Halere, badira iritzi kontrajarriak dituzten beste zenbait aditu ere. Hala, Licht eta Siegel-ek (2006) diseinatutako iniziatiba ekintzaileak aurrera eramaterakoan nazionalismoaren onurak azpimarratzen dituzte. Ikertzaile horien arabera, nortasun eta balio bereko kultura kolektibo baten gainean eraikitako nazionalismoak EOaren eta familia-enpresen emaitzen arteko erlaziorako bi abantaila izan ditzake: lehenengoa, ospe ona, ekimen horientzat beharrezkoak diren baliabideak eskainiko dituzten hornitzaileen artean; bigarrena, harreman hobeak balio-kate bereko enpresen artean, konfidentzialtasunari dagokionez. Hori guztia kontuan hartuta, badirudi identitatea eta herri baten partaide izateak, beste herrialde ahaltsuagoekin dauzkan harremanen arabera, efektu ezberdinak izan ditzakeela.

Nazionalismoak herri bereko enpresek elkarri laguntzean izan dezakeen efektuari dagokionez, SI enpresa sahararrak ideia hori inolako ezbairik gabe baieztatzen du, 
bere nortasun eta kultura propioarekiko etsaitasun-egoerak lurralde bereko enpresen elkarren arteko laguntza areagotzen duela aipatuz, enpresa-ekimenak martxan jartzerakoan ere agerikoa dena. Horrek ez du esan nahi kanpoko enpresekin ez denik akordiorik sinatuko; aitzitik, oso interesgarria izan daiteke hitzarmenaren baldintzak onak baldin badira, baina betiere hitzarmenak oso mesedegarria izan behar du. Etsaitasun-egoeretan errazagoa da egoera inork baino hobeto ulertzen duenari laguntzea, konplizitate-mailak gora egiten baitu. Zentzu horretan, elkarren arteko laguntza handitzen da etsaitasun-maila altuagoa denean: jendea gehiago batzen da, elkarri babesa eskaintzen diote... Hau kontuan harturik, nazionalismoaren efektua eta kulturaren eragina etsaitasun-mailaren menpe dagoela, dela politikaarlokoa dela merkatuaren lehiakortasun-mailakoa, ondoriozta daiteke.

\subsection{Erlijioaren efektuak}

Erlijioak sinesmen eta praktika kulturalen multzoan eragiteaz gain, gizarteharremanetan ere eragiten du (Martez eta Rodríguez, 2004). Erlijioak banakoen balio kulturaletan eta sinesmenetan eragina dauka (Basu eta Altinay 2002). Testuinguru erlijiosoak, halaber, gizabanakoen zein enpresen berrikuntzarako joeran, sormenean eta lehiakortasunean eragiten du (Gotsis eta Kortezi 2009). Horregatik, zenbait ikertzaile erlijioak ekintzailetzarako joeran duen efektua azaltzen saiatu dira (Carsud eta Brännback, 2012).

Mendebaldeko Saharan islama erlijio zabalduena denez, ikerlan honetan islamak enpresetan daukan eragina aztertu da. Sabah, Carsud eta Kocak-ek (2014) ekintzailetzari buruzko islamaren oinarrizko ideien errepasoa egin dute, eta aztertutako kasu gehienetan emaitzak kalterako direla esaten dute. Batetik, Cinar-en (2005) lana aipatzen dute, non islamak teknologia berriei zein gizartearen hobekuntzan eragiten duten aldaketei ematen dien bultzada nabarmentzen den. Bestetik, Fattah eta Butterfied-en (2006) aburuz islama enpresen berrikuntzarentzat balazta garrantzitsua da. Horren arabera, islamaren eragina bere kokapenaren arabera ezberdina izan daitekeela ondoriozta daiteke (Fattah eta Butterfied, 2006). Mendebaldeko Saharako lau enpresen analisi honetan, saharar enpresek islam erlijioa EOaren arrakasta lortzen lagun dezakeen palanka bat bezala ulertzen dutela ikustea oso interesgarria da, haien aburuz horrek gizarteak aurrerapausoak ematea baitakar, ezarritako ordena apurtzea ahalbidetzen duten berrikuntzek ez bezala. Sabah et al.-en (2014) turkiar enpresen analisian, erlijioa islamari oso atxikimendu handia dioten enpresak batu eta elkarlanean aritzeko balio duen ukiezina da. Gainera, atxikimendu handi hori ematen ez den beste herrialdeekin alderatuta, zenbait arlo garrantzitsuri begira ulermen-maila handiagoa sustatzen dela aipatzen dute (Ramadan garaian lana-familia-erlijioa bateragarritasuna, adibidez).

Hori gutxi balitz bezala, islamak enpresei ikuspuntu kolektibista bat eskaintzen die, zeina, energia- eta denbora-baliabide asko kontsumitzeaz gain, konpromiso eta talde-lan handia eskatzen duten proiektu berriak hasteko eta garatzeko laguntza handikoa izan daitekeen (Yan eta Sorenson, 2006). SAkoek txikitan erlijioak irakatsitako balioak, errespetua eta konpromisoa, besteak beste, talde-lanerako joeran islatzen direla diote. Horrela, islamak bultzatzen duen ikuspuntu kolektibistak 
enpresaren proiektu ezberdinetan pertsona guztien inplikazioa handitzen laguntzen du. Islamak lanarekiko alfertasuna desohoretzat aitortzea eta lanarekiko ardura indar bezala ikusten duela kontuan hartuz, ondoriozta daiteke erlijioak eragin positiboa duela EOaren eta familia-enpresen emaitzen arteko erlazioan. Aurkikuntza hauek, Yousef (2001) eta Furnham, Petrides, Tsaousis, Pappas eta Garrod-en (2005) lanetan agertzen diren ondorioen ildotik doaz, non islama trabak eta akatsak saihesteko baliagarria den eta elkarlana bultzatzen duela baieztatzen den.

Hala ere, Ali-k (1995) nabarmentzen du islamak aurrez ezarritako ordena, egitura hierarkikoak eta erabakiak hartzerakoan zentralizazioa bultzatzen dituela; kasu gehienetan, erabakiak hartzen dituena familiakoa den zuzendari bat izanik. Horrek estrategien diseinuan malgutasun-galera eta errealitatearen irudikapen zurrunagoen aukeraketa adierazten du, familia-enpresetan ekimen ekintzaileen arrakasta eragotziz. SOkoen ustetan, ordea, hierarkiak eta enpresaren egitura zurrunak haien ekimen ekintzaileak martxan jartzeko punturen bat eragotzi ahal duten arren, ekimen horiei bultzada bat ematea ez omen dago hainbeste erlijioak esaten duenaren menpe, baizik eta enpresaren jabearen izaeraren menpe.

Horren arabera, erlijioak EOaren eta familia-enpresen emaitzen erlazioan daukan eraginari dagokionez, ikerlan honetan ondoriozta daiteke erlazio hori alda dezaketen bi faktore daudela: lehena, erlijioarekiko atxikimendu-mailak garrantzi handia dauka enpresen ekintzailetza-joeretatik eratorritako emaitzen lorpenean edo eragozpenean. Bigarrenik, islamak, gaur egun, eragin nabarmena dauka Mendebaldeko Saharan azaldutako arlo kultural eta usadioetan. Arestian aipatutako guztiagatik, oso nabarmenak dira EOaren eta familia-enpresen emaitzen arteko erlazioan islamak izan ditzakeen efektu positiboak (konpromisoa, elkarlana eta kolektibismoa, batik bat) eta ezinbestekoak izan daitezke ekintzailetza-ekimenak aurrera eramaterakoan.

\section{Ondorioak}

Ikerlan honek, Mendebaldeko Saharako lau enpresatan oinarriturik, enpresaz gaindiko faktoreen eragina orientazio ekintzailean aztertzen du bai eta horrek familiaenpresen emaitzetan daukan efektu positiboa ere. Konkretuki ikertzen du historiak, testuinguru politikoak, egitura eta garapen ekonomikoak, kulturak eta usadioak, eta erlijioak nola eragiten duten, joera ekintzaileak familia-enpresen emaitzetan arrakasta izateko. Hau berez, familia-enpresa eta ekintzailetza-zientzien arloan ekarpen argia da. Ondorioei dagokienez, segidan garrantzitsuenak aipatuko dira:

- Etsaitasuna. Lehen joera ekintzaileentzako bultzadatzat hartzen zenak ezin du EOaren eta familia-enpresen emaitzen arteko erlazioan eraginik izan, egonkortasun politikoaren berme minimorik ez badago.

- EOaren bidez lortutako berrikuntzak garapen-bidean dauden ekonomietan etorkizunerako errentak lortzen laguntzen du, zeina epe luzeagoko garapen ekonomiko iraunkorra eskuratzeko bide emankorra den. 
- Nazionalismoak eta honek kulturan duen efektuak EOaren eta familiaenpresen emaitzen arteko erlazioan duten eragina kanpo-faktoreen menpe dago: erlazio politikoak eta merkatuko harremanak, besteak beste.

- Konpromisoa, elkarlana eta ikuspegi kolektibista islamaren balioak dira, zeinek EOaren eta Saharako familia-enpresen emaitzen arteko erlazioan efektu positiboak dituzten.

Mendebaldeko Sahararen testuinguruan erdietsiriko emaitzetatik eratorritako ondorioek ere badute aplikagarritasunik lurralde honetako bestelako enpresa motetan (familia-enpresak ez diren horietan). Hala, etsaitasunak, garapen-bidean dauden ekonomien egiturak berak eta erlijioak zein nazionalismoak ere eragin zuzena izango dute EOak ekitaldiko emaitzetan izan lezakeen efektuan. Izan ere, aztertutako faktore hauen eraginak enpresaz gaindiko efektua du. Halere, familiaenpresen ekosistema hertsiagoak balio kultural eta erlijiosoen transmisioa eta haren garrantzia biderka dezake beste enpresa hauekin alderatuz gero. Bestalde, ikerlan honetako emaitzak antzeko ezaugarriak dituzten beste zenbait herrialdetan partzialki aplikagarriak izan daitezke. Aztertutako lau faktoreak beste herrialde batean maila berean eta era berean gertatzea oso ohikoa ez den arren, ez da horren zaila horietako batzuk Mendebaldeko Sahararekin antzekotasun nabariak dituzten herrialdeetan gertatzea. Hala, egoera politiko ezegonkorra duten herrialdeetan, egitura ekonomiko ahula daukatenetan, zein erlijio eta identitate propioek paper irmoa jokatzen dutenetan (tokian tokiko ezaugarri propioekin) baliagarriak izan daitezke ikerlan honetatik eratorritako ondorioak.

Amaitzeko, ikerlan honek zenbait muga dituen arren, hauek etorkizuneko ikerketak egiteko aukeratzat har daitezke. Muga horietako bat, analisi honen laginaren tamaina dela azpimarratu beharra dago. Hortaz, azterlan hau beste lan handiago batentzako abiapuntutzat uler daiteke, zeinak lagin zabalago baten bidez, ikertutako faktoreen eraginez gain, teknika kuantitatibo baten bidez beste barnefaktore batzuk ere neur ditzakeen.

\section{Erreferentziak}

Ali, A.J. (1995): "Cultural discontinuity and Arab management thought». International Studies of Management \& Organization, 25(3), 7-30.

Anderson, B.S. eta Eshima, Y. (2013): «The influence of firm age and intangible resources on the relationship between entrepreneurial orientation and firm growth among Japanese SMEs», Journal of Business Venturing, 28(3), 413-429.

Archibugi, D.; Filippetti, A. eta Frenz, M. (2013): «Economic crisis and innovation: Is destruction prevailing over accumulation?», Research Policy, 42(2), 303-314.

Arora, A. eta Gambardella, A. (2005): «The globalization of the software industry: perspectives and opportunities for developed and developing countries", Innovation policy and the economy, 5, 1-32.

Arzubiaga, U.; Iturralde, T. eta Maseda, A. (2012): «La medición de la Orientación Emprendedora en las empresas familiares: una revisión crítica de la literatura", Revista de Empresa Familiar, 2(2), 57-71. 
Baker, W.E. eta Sinkula, J.M. (2009): «The complementary effects of market orientation and entrepreneurial orientation on profitability in small businesses», Journal of Small Business Management, 47(4), 443-464.

Balabanis, G.; Diamantopoulos, A.; Mueller, R.D. eta Melewar, T.C. (2001): «The impact of nationalism, patriotism and internationalism on consumer ethnocentric tendencies», Journal of International Business Studies, 32(1), 157-175.

Basu, A. eta Altinay, E. (2002): «The interaction between culture and entrepreneurship in London's immigrant businesses», International Small Business Journal, 20(4), 371-393.

Breugst, N.; Patzelt, H. eta Rathgeber, P. (2015): «How should we divide the pie? Equity distribution and its impact on entrepreneurial teams", Journal of Business Venturing, 30(1), 66-94.

Burgess, S.M. eta Steenkamp, J.B.E. (2006): «Marketing renaissance: How research in emerging markets advances marketing science and practice», International Journal of Research in Marketing, 23(4), 337-356.

Carsrud, A.L. eta Brännback, M. (2012): «Where have we been and where we should be going in family business research», in Understanding Family Businesses, Springer, New York, NY, 1-7.

Casillas, J.C.; Moreno, A.M. eta Barbero, J.L. (2011): «Entrepreneurial orientation of family firms: Family and environmental dimensions», Journal of Family Business Strategy, 2(2), 90-100.

Cassia, L.; De Massis, A. eta Pizzurno, E. (2012): «Strategic innovation and new product development in family firms: An empirically grounded theoretical framework», International Journal of Entrepreneurial Behavior \& Research, 18(2), 198-232.

Chirico, F. eta Nordqvist, M. (2010): «Dynamic capabilities and transgenerational value creation in family firms: The role of organizational culture», International Small Business Journal, 28(5), 487-504.

Çinar, A. (2005): Modernity, Islam, and secularism in Turkey: Bodies, places, and time (Vol. 14), $U$ of Minnesota Press.

Corell, H. (2015): «The Responsibility of the UN Security Council in the Case of Western Sahara», International Judicial Review.

Covin, J.G.; Green, K.M. eta Slevin, D.P. (2006): «Strategic process effects on the entrepreneurial orientation-sales growth rate relationship», Entrepreneurship Theory and Practice, 30(1), 57-81.

Covin, J.G. eta Slevin, D.P. (1989): «Strategic management of small firms in hostile and benign environments», Strategic Management Journal, 10(1), 75-87.

(1991): «A conceptual model of entrepreneurship as firm behavior», Entrepreneurship Theory and Practice, 16(1), 7-25.

Covin, J.G. eta Wales, W.J. (2012): «The measurement of entrepreneurial orientation», Entrepreneurship Theory and Practice, 36(4), 677-702.

Cruz, C. eta Nordqvist, M. (2012): «Entrepreneurial orientation in family firms: A generational perspective», Small Business Economics, 38(1), 33-49.

Dimitratos, P.; Lioukas, S. eta Carter, S. (2004): «The relationship between entrepreneurship and international performance: the importance of domestic environment», International Business Review, 13(1), 19-41.

Eisenhardt, K.M. eta Graebner, M.E. (2007): «Theory building from cases: Opportunities and challenges», Academy of Management Journal, 50(1), 25-32.

Eisenhardt, K.M. (1989): «Building theories from case study research», Academy of Management Review, 14(4), 532-550. 
Es-Sweyih, M.I. eta uld Ismail, M.F. (1998): El primer Estado del Sáhara Occidental, Ediciones L. Harmattan, Paris.

Fattah, M.A. eta Butterfield, J. (2006): «Muslim cultural entrepreneurs and the democracy debate», Critique: Critical Middle Eastern Studies, 15(1), 49-78.

Furnham, A.; Petrides, K.V.; Tsaousis, I.; Pappas, K. eta Garrod, D. (2005): «A cross-cultural investigation into the relationships between personality traits and work values», The Journal of Psychology, 139(1), 5-32.

García Guindo, M. (2016): «Sahara Occidental: los factores económicos como detonante de la violencia organizada», Index de Enfermería, 25(3), 190-193.

Glaser, B. eta Strauss, A. (1967): The discovery of grounded theory, Aldine de Gruyter, New York.

Gotsis, G. eta Kortezi, Z. (2009): «The impact of Greek Orthodoxy on entrepreneurship: a theoretical framework», Journal of Enterprising Communities: People and Places in the Global Economy, 3(2), 152-175.

Goulding, C. (2009): «Grounded theory perspectives in organizational research», The SAGE handbook of organizational research methods, 381-394.

Hughes, M. eta Morgan, R.E. (2007): «Deconstructing the relationship between entrepreneurial orientation and business performance at the embryonic stage of firm growth», Industrial Marketing Management, 36(5), 651-661.

Hult, G.T.M.; Snow, C.C. eta Kandemir, D. (2003): «The role of entrepreneurship in building cultural competitiveness in different organizational types», Journal of Management, 29(3), 401-426.

Jaskiewicz, P.; Combs, J.G. eta Rau, S.B. (2015): «Entrepreneurial legacy: Toward a theory of how some family firms nurture transgenerational entrepreneurship», Journal of Business Venturing, 30(1), 29-49.

Jennings, J.E.; Edwards, T.; Jennings, P.D. eta Delbridge, R. (2015): «Emotional arousal and entrepreneurial outcomes: Combining qualitative methods to elaborate theory», Journal of Business Venturing, 30(1), 113-130.

Kellermanns, F.W. eta Eddleston, K.A. (2006): «Corporate entrepreneurship in family firms: A family perspective», Entrepreneurship Theory and Practice, 30(6), 809-830.

Kellermanns, F.W.; Eddleston, K.A.; Barnett, T. eta Pearson, A. (2008): «An exploratory study of family member characteristics and involvement: Effects on entrepreneurial behavior in the family firm», Family Business Review, 21(1), 1-14.

Khavul, S.; Bruton, G.D. eta Wood, E. (2009): “Informal family business in Africa», Entrepreneurship Theory and Practice, 33(6), 1.219-1.238.

Kingsbury, D. (2016): Western Sahara: international law, justice and natural resources, Routledge.

Kirca, A.H.; Jayachandran, S. eta Bearden, W.O. (2005): «Market orientation: A meta-analytic review and assessment of its antecedents and impact on performance», Journal of Marketing, 69(2), 24-41.

Kollmann, T. eta Stöckmann, C. (2014): «Filling the entrepreneurial orientation- performance gap: The mediating effects of exploratory and exploitative innovations», Entrepreneurship Theory and Practice, 38(5), 1001-1026.

Liceras, J.S. (2014): International law and the Western Sahara conflict, Wolf Legal Publishers (WLP).

Licht, A. eta Siegel, J. (2006): «The social dimensions of entrepreneurship», in Mark Casson eta Bernard Yeung (ed.), Oxford Handbook of Entrepreneurship, Oxford University Press, Oxford.

Lumpkin, G.T. eta Dess, G.G. (1996): «Clarifying the entrepreneurial orientation construct and linking it to performance», Academy of Management Review, 21(1), 135-172. 
, (2001): «Linking two dimensions of entrepreneurial orientation to firm performance: The moderating role of environment and industry life cycle», Journal of Business Venturing, 16(5), 429-451.

Lumpkin, G.T.; Brigham, K.H. eta Moss, T.W. (2010): «Long-term orientation: Implications for the entrepreneurial orientation and performance of family businesses", Entrepreneurship and Regional Development, 22(3-4), 241-264.

Marchi, V.D.; Maria, E.D. eta Micelli, S. (2013): «Environmental strategies, upgrading and competitive advantage in global value chains", Business Strategy and the Environment, 22(1), 62-72.

Martìn, J.C.G. eta Picón, J.I.R. (2015): «Hacia una contrahistoria del Sahara Occidental», Les Cahiers d'EMAM. Études sur le Monde Arabe et la Méditerranée, 24-25.

Miller, D. (1983): «The correlates of entrepreneurship in three types of firms», Management Science, 29(7), 770-791.

Moreno, A.M. eta Casillas, J.C. (2008): «Entrepreneurial orientation and growth of SMEs: A causal model», Entrepreneurship theory and practice, 32(3), 507- 528.

Mundy, J. (2017): «The Geopolitical Functions of the Western Sahara Conflict: US Hegemony, Moroccan Stability and Sahrawi Strategies of Resistance», in Global, Regional and Local Dimensions of Western Sahara's Protracted Decolonization, Palgrave Macmillan US, 53-78.

Naldi, L.; Nordqvist, M.; Sjöberg, K. eta Wiklund, J. (2007): «Entrepreneurial orientation, risk taking, and performance in family firms», Family Business Review, 20(1), 33-47.

Paunov, C. (2012): «The global crisis and firms' investments in innovation», Research Policy, 41(1), 24-35.

Pistrui, D.; Huang, W.V.; Welsch, H.P. eta Jing, Z. (2006): «25 Family and cultural forces: shaping entrepreneurship and SME development in China», Handbook of research on family business, 460.

Rauch, A.; Wiklund, J.; Lumpkin, G.T. eta Frese, M. (2009): «Entrepreneurial orientation and business performance: An assessment of past research and suggestions for the future», Entrepreneurship Theory and Practice, 33(3), 761-787.

Sabah, S.; Carsrud, A.L. eta Kocak, A. (2014): «The impact of cultural openness, religion, and nationalism on entrepreneurial intensity: Six prototypical cases of Turkish family firms», Journal of Small Business Management, 52(2), 306-324.

Saeed, S.; Yousafzai, S.Y. eta Engelen, A. (2014): «On cultural and macroeconomic contingencies of the entrepreneurial orientation-performance relationship», Entrepreneurship Theory and Practice, 38(2), 255-290.

Sciascia, S.; Mazzola, P. eta Chirico, F. (2013): «Generational involvement in the top management team of family firms: Exploring nonlinear effects on entrepreneurial orientation», Entrepreneurship Theory and Practice, 37(1), 69-85.

Semrau, T.; Ambos, T. eta Kraus, S. (2016): «Entrepreneurial orientation and SME performance across societal cultures: An international study», Journal of Business Research, 69(5), 1.928-1.932.

Sharma, P.; Chrisman, J.J. eta Gersick, K.E. (2012): «25 years of family business review: reflections on the past and perspectives for the future», Family Business Review, 25(1), 5-15

Smith, J.J. (2013): «Fishing for Self-Determination: European Fisheries and Western Sahara», The Case of Ocean Resources in Africa's Last Colony.

(2015): «The taking of the Sahara: the role of natural resources in the continuing occupation of Western Sahara», Global Change, Peace \& Security, 27(3), 263284. 
Stam, W. eta Elfring, T. (2008): «Entrepreneurial orientation and new venture performance: The moderating role of intra-and extraindustry social capital», Academy of Management Journal, 51(1), 97-111.

Suddaby, R.; Bruton, G.D. eta Si, S.X. (2015): «Entrepreneurship through a qualitative lens: Insights on the construction and/or discovery of entrepreneurial opportunity", Journal of Business Venturing, 30(1), 1-10.

Tang, J.; Tang, Z.; Marino, L.D.; Zhang, Y. eta Li, Q. (2008): «Exploring an inverted U-Shape relationship between entrepreneurial orientation and performance in Chinese ventures», Entrepreneurship Theory and Practice, 32(1), 219-239.

Tsui, A.S.; Nifadkar, S.S. eta Ou, A.Y. (2007): «Cross-national, cross-cultural organizational behavior research: Advances, gaps, and recommendations", Journal of Management, 33(3), 426-478.

Van Doorn, S.; Jansen, J.J.; Van den Bosch, F.A. eta Volberda, H.W. (2013): «Entrepreneurial orientation and firm performance: Drawing attention to the senior team», Journal of Product Innovation Management, 30(5), 821-836.

Wang, C.L. (2008): «Entrepreneurial orientation, learning orientation, and firm performance», Entrepreneurship Theory and Practice, 32(4), 635-657.

Watch, W.S.R. (2015): P for Plunder: Morocco's Exports of Phosphates from Occupied Western Sahara, 2.012-2.013>>.

Wiklund, J. eta Shepherd, D. (2003): «Knowledge based resources, entrepreneurial orientation, and the performance of small and medium sized businesses", Strategic Management Journal, 24(13), 1.307-1.314.

Woodside, A.G. eta Baxter, R. (2013): «Achieving accuracy, generalization-to-contexts, and complexity in theories of business-to-business decision processes», Industrial Marketing Management, 42(3), 382-393.

Wright, M.; Pruthi, S. eta Lockett, A. (2005): «International venture capital research: From cross-country comparisons to crossing borders», International Journal of Management Reviews, 7(3), 135-165.

Yan, J. eta Sorenson, R. (2006): "The effect of Confucian values on succession in family business», Family Business Review, 19(3), 235-250.

Yin, R.K. (2003): Case study research: Design and methods, Sage, Thousand Oaks, CA.

Yousef, D.A. (2001): «Islamic work ethic-A moderator between organizational commitment and job satisfaction in a cross-cultural context», Personnel Review, 30(2), 152169.

Zahra, S.A. (1991): «Predictors and financial outcomes of corporate entrepreneurship: An exploratory study», Journal of Business Venturing, 6(4), 259-285.

Zahra, S.A.; Hayton, J.C. eta Salvato, C. (2004): «Entrepreneurship in Family vs. Non-Family Firms: A Resource-Based Analysis of the Effect of Organizational Culture», Entrepreneurship Theory and Practice, 28(4), 363-381.

Zunes, S. eta Mundy, J. (2010): Western Sahara: War, nationalism, and conflict irresolution, Syracuse University Press. 

